\title{
Induction of apoptosis in human prostate cancer cell line, PC3, by 3,3'-diindolylmethane through the mitochondrial pathway
}

\author{
M Nachshon-Kedmi', S Yannai' and FA Fares ${ }^{*, 2,3}$ \\ 'Faculty of Food Engineering and Biotechnology, Technion-Israel Institute of Technology, Haifa 32000, Israel; ${ }^{2}$ Department of Biochemistry and Molecular \\ Genetics, Carmel Medical Center, Haifa, Israel; ${ }^{3}$ Faculty of Medicine, Technion-Israel Institute of Technology, Haifa, Israel
}

Prostate cancer is the most common malignancy and the second leading cause of male death in Western countries. Prostate cancer mortality results from metastases to the bones and lymph nodes and progression from androgen-dependent to androgenindependent disease. Although androgen ablation was found to be effective in treating androgen-dependent prostate cancer, no effective life-prolonging therapy is available for androgen-independent cancer. Epidemiological studies have shown a strong correlation between consumption of cruciferous vegetables and a lower risk of prostate cancer. These vegetables contain glucosinolates, which during metabolism give rise to several breakdown products, mainly indole-3-carbinol (I3C), which may be condensed to polymeric products, especially 3,3'-diindolylmethane (DIM). It was previously shown that these indole derivatives have significant inhibitory effects in several human cancer cell lines, which are exerted through induction of apoptosis. We have previously reported that I3C and DIM induce apoptosis in prostate cancer cell lines through p53-, bax-, bcl-2- and fasL-independent pathways. The objective of this study was examination of the apoptotic pathways that may be involved in the effect of DIM in the androgenindependent prostate cancer cell line, PC3, in vitro. Our results suggest that DIM induces apoptosis in PC3 cells, through the mitochondrial pathway, which involves the translocation of cytochrome $c$ from the mitochondria to the cytosol and the activation of initiator caspase, 9, and effector caspases, 3 and 6, leading to poly ADP-ribose polymerase (PARP) cleavage and induction of apoptosis. Our findings may lead to the development of new therapeutic strategies for the treatment of androgen-independent prostate cancer.

British Journal of Cancer (2004) 9I, 1358-1363. doi:I0.1038/sj.bjc.6602 I45 www.bjcancer.com

Published online 24 August 2004

(c) 2004 Cancer Research UK

Keywords: 3,3'-diindolylmethane; apoptosis; caspases; PC3 cells; prostate cancer

Prostate cancer is the most common diagnosed malignancy and the second leading cause of male death in Western countries (Tang and Porter, 1997; Crawford, 2003). Mortality from prostate cancer results from metastases to the bones and lymph nodes and progression from androgen-dependent disease to androgenindependent prostatic growth (Bruckheimer and Kyprianou, 2000). The androgen-dependent phase of prostate cancer may be effectively treated with androgen ablation therapies, which cause involution of the prostate gland, as a result of inhibition of cellular proliferation and stimulation of apoptosis (Tang and Porter, 1997). However, in most of the patients, progression to the lethal stage of androgen independence, for which there is no effective lifeprolonging therapy, eventually occurs (Tang and Porter, 1997; Abate-Shen and Shen, 2000). Hence, intense investigations emerge, trying to better understand androgen-independent disease and seeking effective means against this type of cancer.

Several epidemiological studies have shown a strong correlation between consumption of diets rich in fruits and vegetables and a lower risk of various cancers (Dragsted et al, 1993; Tavani and La Vecchia, 1995). A number of studies have demonstrated a reduced

*Correspondence: Dr FA Fares, Department of Biochemistry and Molecular Genetics, Carmel Medical Center, Michal Street 7, Haifa 34362, Israel; E-mail: fares@clalit.org.il

Revised 18 June 2004; accepted 16 July 2004; published online 24 August 2004 risk of developing prostate cancer in humans consuming cruciferous vegetables, such as broccoli, Brussels sprouts, cabbage and cauliflower (Jain et al, 1999; Cohen et al, 2000; Kolonel et al, 2000). These vegetables contain glucosinolates which, during metabolism, give rise to several breakdown products, mainly indole-3-carbinol (I3C) (Bradfield and Bjeldanes, 1987; Verhoeven et al, 1997). In a low $\mathrm{pH}$ environment, I3C is converted into polymeric products, among which $3,3^{\prime}$-diindolylmethane (DIM) is the main one (Bradfield and Bjeldanes, 1987; De Kruif et al, 1991). It was previously shown that these indole derivatives have inhibitory effects on the viability and proliferation of several human cancer cell lines (Ge et al, 1996; Fares et al, 1998; Bonnesen et al, 2001; Chen et al, 2001; Chinni et al, 2001; Kedmi et al, 2003). These studies demonstrated that the indolic compounds exert their effects in the cancer cells through the induction of an apoptotic cell response.

Apoptosis, a programmed cell death, is critical for normal development, function and homeostasis of multicellular organisms, and is regulated by the expression of multiple genes such as p53, bcl-2 family members and cytochrome $c$ (Cosulich et al, 1999; Sheikh and Fornace, 2000). Signalling for apoptosis occurs through multiple independent pathways that are initiated by diverse extracellular and intracellular factors (Strasser et al, 2000). Activation of a family of cysteine proteases, caspases, plays a critical role in the execution of all apoptosis signalling pathways (Nunez et al, 1998; Strasser et al, 2000). These enzymes cleave vital 
cellular proteins, resulting in distinct biochemical and morphological features, including cell shrinkage, chromatin condensation and DNA fragmentation (Bortner et al, 1995; Strasser et al, 2000).

We and others (Chinni et al, 2001; Kedmi et al, 2003) have previously shown that indole derivatives originating from cruciferous vegetables, I3C and DIM, have significant inhibitory effects in prostate cancer cell lines, which are carried out by induction of apoptosis. The purpose of our current study was to examine the apoptotic pathways that may be involved in the effect of DIM in the androgen-independent prostate cancer cell line, $\mathrm{PC} 3$, in vitro.

\section{MATERIALS AND METHODS}

\section{Materials}

$3,3^{\prime}$-Diindolylmethane was purchased from Designed Nutritional Products (USA). Cell culture media and reagents were obtained from Biological Industries (Beit Haemek, Israel). Anti-caspase 3 and anti-cytochrome $c$ monoclonal antibodies were purchased from Santa Cruz Biotechnology (Santa Cruz, CA, USA). Anticaspase 6 and 9 monoclonal antibodies were purchased from Medical and Biological Laboratories (Japan). Anti-caspase 8 monoclonal antibody was purchased from Oncogene (Boston, MA, USA). Anti-actin monoclonal antibody was purchased from ICN Biomedicals (Aurora, OH, USA). Secondary antibody peroxidase-conjugated goat anti-mouse IgG was purchased from Jackson Immune Research Laboratories (West Grove, PA, USA). Colorimetric kits for the detection of caspase activity were purchased from Calbiochem (San Diego, CA, USA). All other chemicals were purchased from Sigma or other local sources.

\section{Cell culture}

Human prostate cancer cell line, PC3 (deficient in p53 gene, androgen-independent, poorly differentiated), was obtained from the American Type Culture Collection, Manassas, VA, USA. Cells were grown in F-12 medium supplemented with $10 \%$ heatinactivated foetal calf serum, and $100 \mathrm{U} \mathrm{ml}^{-1}$ penicillin/streptomycin (Beit Haemek, Israel). Cells were cultured at $37^{\circ} \mathrm{C}$ in an atmosphere of $95 \%$ air and $5 \%$ of $\mathrm{CO}_{2}$.

\section{3,3'-Diindolylmethane stock solution}

$3,3^{\prime}$-Diindolylmethane stock solution was prepared by dissolving DIM powder in DMSO to yield a final concentration of $0.1 \mathrm{M}$. The final concentration of DMSO in the culture medium was $0.08 \%$ $\left(\mathrm{v} \mathrm{v}^{-1}\right)$. This concentration of DMSO was established as nontoxic to any cell line.

\section{Total protein extraction}

PC3 cells were treated with $10 \mathrm{ml}$ of culture medium containing $75 \mu \mathrm{M}$ DIM for $8,16,24,48$ and $72 \mathrm{~h}$. The control cells were treated with $0.08 \%\left(\mathrm{vv}^{-1}\right)$ of DMSO solution. At the end of each treatment, cells were collected and their total protein fraction was extracted as described previously (Kedmi et al, 2003). Protein concentrations of the cell lysates were quantified by the method of Bradford (1976).

\section{Cytosol protein extraction}

PC3 cells were treated with $75 \mu \mathrm{M}$ DIM for $8,16,24,48$ and $72 \mathrm{~h}$. At the end of each treatment, cells were harvested and their cytosol proteins were extracted, as described earlier (Bossy-Wetzel et al, 1998). Total cytosol proteins were precipitated with $10 \%$ TCA and harvested by centrifugation at $10000 \mathrm{~g}$ and $4{ }^{\circ} \mathrm{C}$ for $15 \mathrm{~min}$. The pellets were resuspended in $0.4 \mathrm{M} \mathrm{NaOH}$ to give a final protein concentration of $3 \mathrm{mg} \mathrm{m}^{-1}$, as described previously (Grubb et al, 2001).

\section{Western blot analysis}

In all, $60 \mu \mathrm{g}$ of protein from each sample were separated by $15 \%$ SDS - polyacrylamide gels (SDS - PAGE), electrophoretically transferred onto a nitrocellulose membrane filter and incubated with specific antibodies, as described earlier (Kedmi et al, 2003). Results were quantified by densitometer analysis (Zilber Lurma, France) using BiolD software, and are expressed as percentages of the respective controls. Actin level (as standard protein occurring naturally in these cells) was used as a reference.

\section{Caspase colorimetric assay}

PC3 cells were treated with $75 \mu \mathrm{M}$ DIM for $8,16,24,48$ and $72 \mathrm{~h}$. At the end of each treatment, cells were collected, proteins were extracted and the activity of caspases 3, 6, 8 and 9 was determined using colorimetric kits, according to the manufacturer's instructions (Calbiochem).

\section{Statistics}

Western blot analyses were repeated three times, and the quantitative evaluation of the protein levels using densitometeric analysis is presented as means \pm standard error (s.e.). Caspase colorimetric activity determination was repeated three times, each performed in duplicate, and the data are presented as means \pm s.e. Statistical analyses of the differences between controls and treated groups were performed using Student's $t$-test.

\section{RESULTS}

\section{Effect of DIM on caspase protein levels and activities}

In this study, we examined the effect of DIM on the levels and activities of initiator and effector caspases, in order to better characterise the pathway through which DIM exerts its apoptotic effects in these cells. PC3 cells were treated with $75 \mu \mathrm{M}$ DIM for 8 , $16,24,48$ and $72 \mathrm{~h}$. At the end of each treatment, cells were harvested and their total protein fraction was extracted. Determination of caspase 3, 6, 8 and 9 levels was conducted using Western blotting analysis with a quantitative analysis of three independent blots, using a densitometer, as described in 'Materials and methods'.

The Western blot results shown in Figure 1 indicate the levels of the initiator caspases, pro-caspase 8 and 9. Treatment of PC3 cells with DIM for $72 \mathrm{~h}$ causes a decrease in pro-caspase $8(56 \mathrm{kDa})$ levels (Figure 1A), which was significant, according to the densitometer analysis $(P<0.01)$, in comparison with the control (Figure 1B). There was also a significant decrease in pro-caspase 9 $(45 \mathrm{kDa})$ levels in these cells after exposure to DIM for $48(P<0.01)$ and $72 \mathrm{~h}(P<0.001)$. Furthermore, the results indicate (Figure $1 \mathrm{~A})$ the appearance of one of the active subunits of caspase $9(35 \mathrm{kDa})$, when cells were treated with DIM for $8 \mathrm{~h}$. The levels of this subunit increase when the cells are exposed to DIM, in a time-dependent manner. This protein is absent from the control group.

Figure 2A indicates a decrease in the levels of both effector caspases, pro-caspase $3(32 \mathrm{kDa})$ and $6(34 \mathrm{kDa})$, after exposure to DIM, in a time-dependent manner. Quantitative analysis of the results observed using a densitometer revealed (Figure 2B) that this decrease was significant when cells were exposed to DIM for 48 or $72 \mathrm{~h}(P<0.001)$ in comparison with the controls.

In order to strengthen the Western blot results, we further examined the activity of the above caspases using a colorimetric detection assay kit with specific caspase substrates, as described in 'Materials and methods'. Figure 3 demonstrates the activity of both effector and initiator caspases in PC3 cells treated with DIM.

Our results indicate a significant increase in the activity of caspase 9 in these cells. The activity of this enzyme was twice that 
A

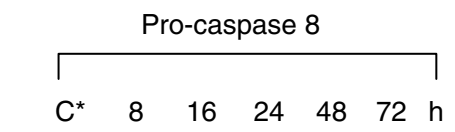

$56 \mathrm{kDa}$

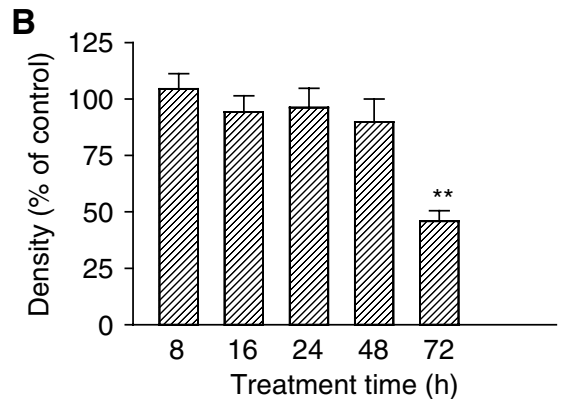

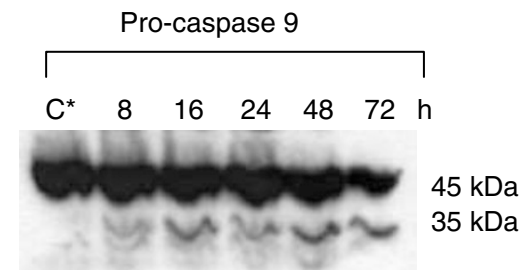

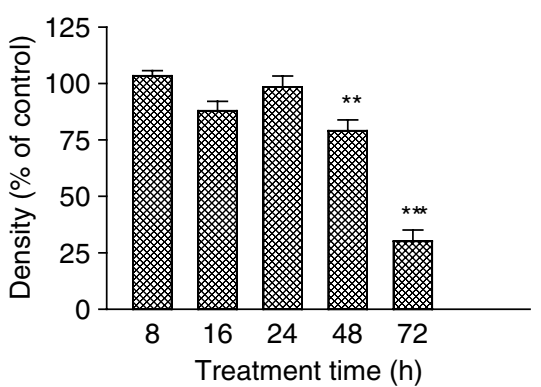

Figure I Pro-caspase 8 and 9 levels following treatment of PC3 cells with $75 \mu \mathrm{M}$ DIM for $8-72 \mathrm{~h}$. Cells were treated with DIM and their total protein fraction was extracted, separated on SDS-PAGE and exposed to specific antibodies using Western blotting, as described in 'Materials and methods'. (A) Western blotting results. $C^{*}$ denotes a representative control group. The figures shown are representatives of three independent experiments. (B) Densitometer results. Data presented are averages of three independent experiments ( \pm s.e.) and are expressed as percentages of the respective controls. *** $P<0.01 ;$ **** $P<0.001$.

A

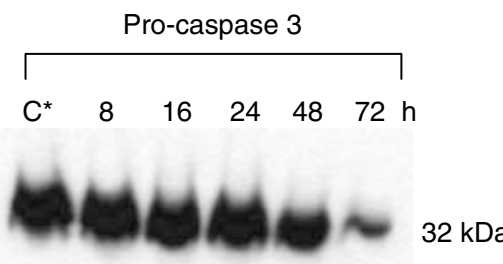

B

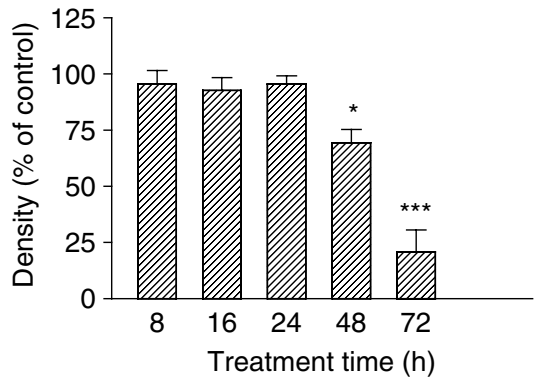

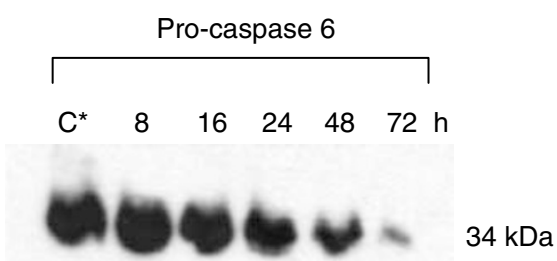

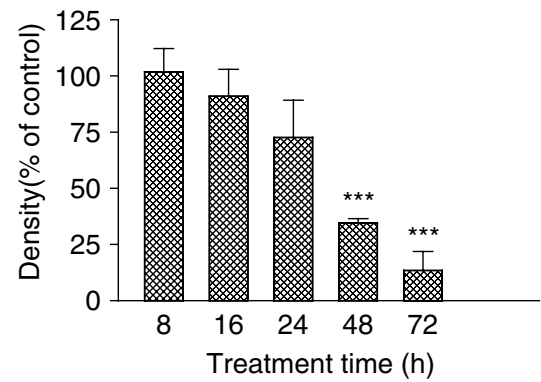

Figure 2 Pro-caspase 3 and 6 levels following treatment of PC 3 cells with $75 \mu \mathrm{M}$ DIM for $8-72 \mathrm{~h}$. The experimental details and the designations of letters $(\mathbf{A}-\mathbf{C})$ were as described for Figure I. $* P<0.05 ; * * * P<0.001$.

of the control when cells were exposed to DIM for $16 \mathrm{~h}$, and it increased with time and reached a level five-fold higher than that of the control after $24 \mathrm{~h}$, nine-fold higher after $48 \mathrm{~h}(P<0.01)$ and 16 -fold higher after $72 \mathrm{~h}(P<0.01)$. The activity of caspase 8 also increased in these cells when exposed to DIM, starting from $24 \mathrm{~h}$ (twice that of the control), and reached a level eight times higher than that of the control after $72 \mathrm{~h}$.

The results also show a significant increase in the activity of caspases 3 and 6 , in a time-dependent manner. These caspase activities were found to be more than $5(P<0.01), 15(P<0.001)$ and $30(P<0.001)$ times higher when the PC3 cells were exposed to DIM for $16-24,48$ and $72 \mathrm{~h}$, respectively, in comparison to the controls.

\section{Release of cytochrome $c$ to the cytosol}

Cytochrome $c$ is a mitochondrial protein, which is released to the cytosol in response to a variety of apoptotic signals and promotes caspase cascade activation through caspase 9 (Nunez et al, 1998). Since our results indicated strong evidence for the activation of caspase 9 in PC3 cells after treatment with DIM, we examined whether the apoptotic response in these cells involves the translocation of cytochrome $c$ from the mitochondria to the cytosol. For this purpose, the protein levels of cytochrome $c$ in the cytosol were examined using Western blotting analysis and specific monoclonal antibody, as described in 'Materials and methods'. The results indicated that treatment of the cells with $75 \mu \mathrm{M}$ DIM induced cytochrome $c$ release to the cytosol after $8 \mathrm{~h}$ 


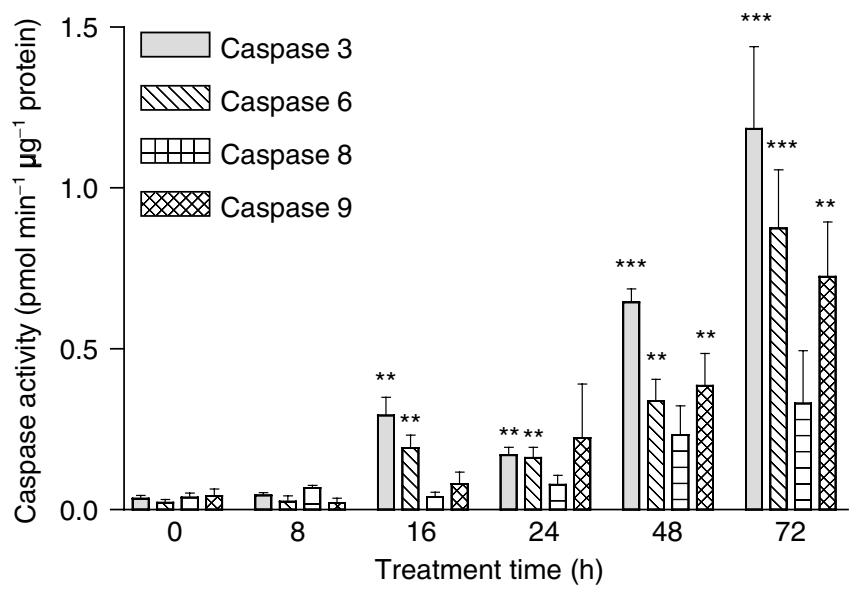

Figure 3 Effect of DIM on caspase activation in PC3 cells. Determination of enzyme activity was applied by a colorimetric assay using specific caspase substrates, as described in 'Materials and methods'. Data presented are averages of three experiments, each conducted in duplicates ( \pm s.e..). ** $P<0.0$ I: **** $P<0.001$

A
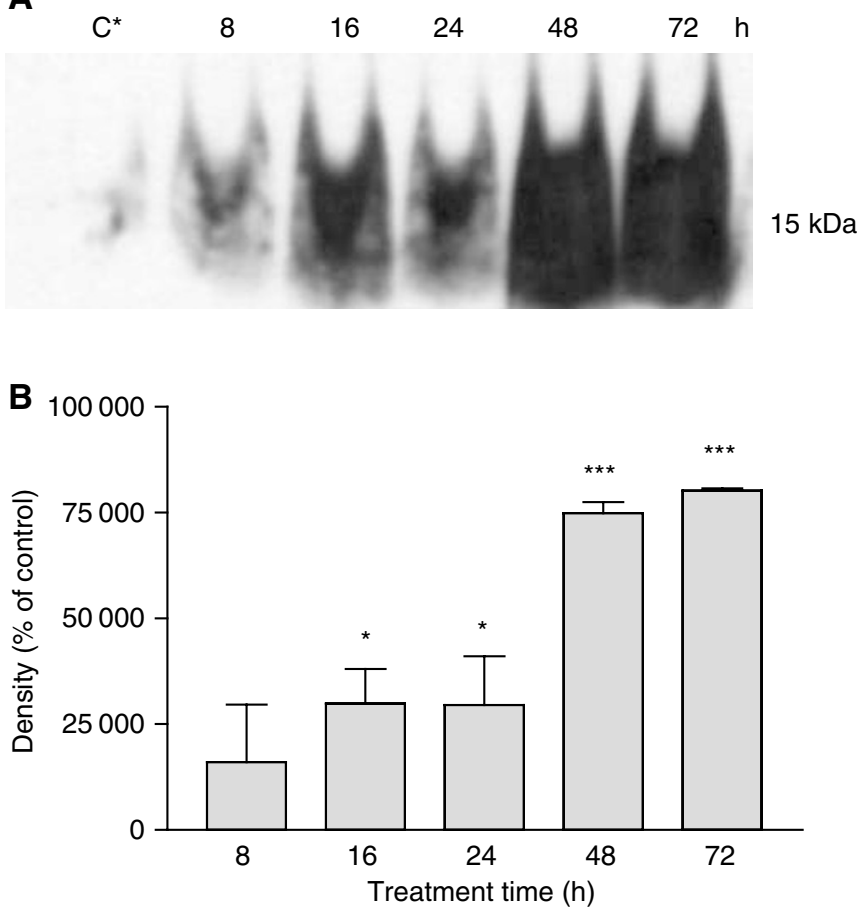

Figure 4 Release of cytochrome $\mathrm{c}$ to the cytosol in PC3 cells treated with $75 \mu \mathrm{M}$ DIM for 8-72 h. Cells were treated with DIM and their cytosol protein fraction was extracted, separated on SDS-PAGE and exposed to specific antibody using Western blotting, as described in 'Materials and methods'. (A) Western blotting results. $C^{*}$ denotes a representative control group. The figure shown is a representative of three independent experiments. (B) Densitometer results. Data presented are averages of three independent experiments $( \pm$ s.e. $)$ and are expressed as percentages of the respective controls. $* P<0.05$; $* * * P<0.001$.

(Figure 4A). This release rose with time of exposure, until reaching a maximum after $48 \mathrm{~h}$. In the control group, only a minimal leakage of this protein was observed. Quantitative results, using a densitometeric analysis, displayed the significance of this protein release (Figure 4B). Treating cells with DIM for 16 and $24 \mathrm{~h}$ caused a significant release of cytochrome $c$ to the cytosol $(P<0.05)$ and this release was greatly increased with exposure times of 48 and $72 \mathrm{~h}(P<0.001)$.

Actin level was used as a reference of a standard protein occurring naturally in these cells (Figure 6). The levels of this protein were equal in each of the samples.

\section{DISCUSSION}

In the present study, we attempted to explore the mechanism of action involved in the beneficial effects of the indole derivative, DIM, on human androgen-independent prostate cancer cell line, PC3. We have previously reported that this indole derivative has a suppressive effect on the growth of prostate as well as breast cancer cell lines. This effect was mediated through the induction of an apoptotic process, as was observed through apoptotic morphological changes and the appearance of a typical DNA ladder within treated cells (Ge et al, 1996; Fares et al, 1998; Kedmi et al, 2003). Furthermore, we found that induction of apoptosis in PC3 cells by DIM occurred through a p53-, bax-, bcl-2- and fasL-independent pathway (Kedmi et al, 2003). In this study, we examined the levels and activities of several caspases in the same cells in response to DIM exposure. Caspases are cysteine proteases which are formed constitutively in the cells and are normally present as inactive proenzymes. Caspases are activated during apoptosis in a selfamplifying cascade (Saraste and Pulkki, 2000). Activation of upstream or initiator caspases, such as caspases 8,9 and 10, by proapoptotic signals leads to the proteolytic activation of downstream or effector caspases 3,6 and 7. The effector caspases cleave a set of vital proteins and, thus, initiate and execute the apoptotic degradation of the cell with the typical morphological and biochemical features. Two major pathways of caspase cascade activation have been characterised. One is initiated by ligation of death receptors and the activation of caspase 8 . In the other, mitochondrial pathway, cytochrome $c$ is released from mitochondria in response to a variety of apoptotic stimuli. In the cytosol, cytochrome $c$ can bind to apaf- 1 and, in the presence of dATP or ATP, it activates caspase 9 (Nunez et al, 1998; Saraste and Pulkki, 2000).

In the current study, we provide evidence that the induction of apoptosis occurring in PC3 cells by DIM is exerted through the mitochondrial pathway. Schematic diagram is presented in Figure 5. DIM triggers cytochrome $c$ translocation from the mitochondria to the cytosol (Figure 4), which promotes the activation of caspase 9, that activates in turn caspases 3 and 6 (Figures 1-3) in a time-dependent manner. These effector caspases are responsible for the cleaving of vital cell proteins such as the PARP protein (Kaufmann et al, 1993). We have previously shown the cleavage of this protein in these cells after exposure to DIM (Kedmi et al, 2003). In addition, there is a slight activation of caspase 8 in these cells as well, which may amplify the apoptotic process. It has previously been reported that caspase 8 may cleave the proapoptotic bcl-2 family member, bid, which translocates to the mitochondria, where it triggers cytochrome $c$ release and the activation of apaf-1/caspase 9 pathway (Lou et al, 1998).

Several investigations have attempted to characterise the pathways involved in the apoptotic responses in several cancer cells exposed to indole derivatives, which are found in cruciferous vegetables. These studies found that such compounds have pleiotropic anticarcinogenic activities and may affect many biochemical pathways. Bonnesen et al (2001) demonstrated that indole compounds originating from crucifers prevent colon cancer cell lines growth through the induction of several detoxification enzymes. Leong et al (2001) reported cytostatic effects of DIM in human endometrial cancer cells, which was mediated by the induction of a transforming growth factor- $\alpha$ expression and signal transduction pathway. Carter et al (2002) showed, using cDNA 
DIM

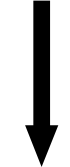

Mitochondria

\section{Cytochrome $c$ release}

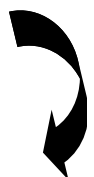

Caspases 3 and 6 activation

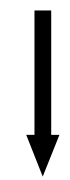

PARP cleavage
Figure 5 Schematic description of the apoptotic pathway in $\mathrm{PC} 3$ cells treated with DIM. Exposure of PC3 cells to DIM triggers the release of cytochrome $c$ from the mitochondria. As a result, initiator caspase 9 is cleaved and activated, and cleaves and activates the effector caspases 3 and 6. These caspases cleave vital cell proteins such as PARP and cause the typical morphological and biochemical characteristics of apoptosis in these cells.

microarrays, that DIM altered the expression of more than 100 genes by at least two-fold in human cervical cancer cells. Many of the stimulated genes encode to transcription factors and proteins involved in signalling, stress response and growth. Recently, Li et al (2003) reported the gene expression profiles of I3C- and DIMtreated PC 3 cells, as was determined by cDNA microarray analysis. These researchers found that these indole derivatives up- and downregulate the expression of a large number of genes, which are significant in the regulation of critical events such as cell growth, cell cycle and apoptosis. Chinni and Sarkar (2002) revealed that I3C-induced apoptosis in PC3 cells is partly mediated by the inhibition of Akt activation pathway and downregulation of BAD and $\mathrm{bcl}-\mathrm{x}_{\mathrm{L}}$. However, it has been reported that $\mathrm{I} 3 \mathrm{C}$ is unstable in tissue culture medium and under acidic conditions, and is partially converted to the very stable compound, DIM (Bradfield and
A
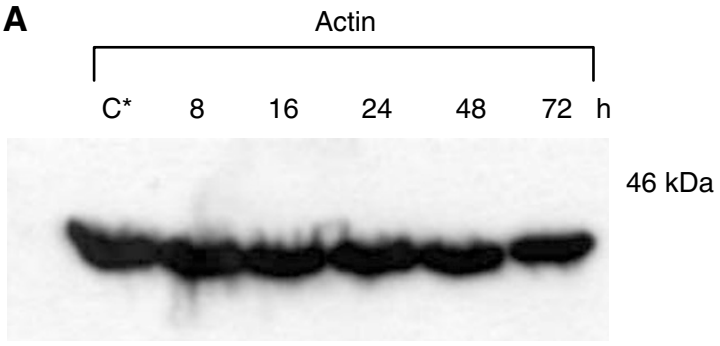

B

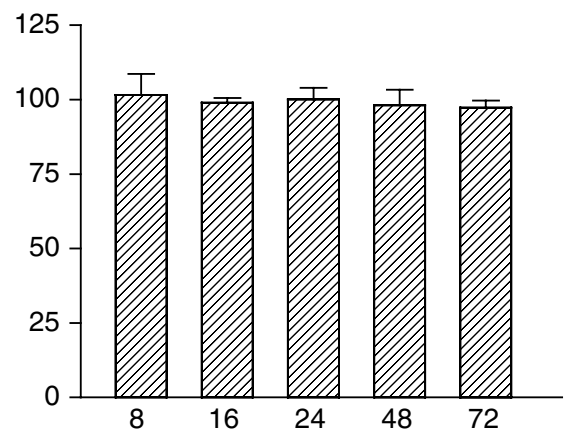

Figure 6 Actin levels following treatment of PC3 cells with $75 \mu \mathrm{M}$ DIM for $8-72 \mathrm{~h}$. The experimental details and the designations of letters $(\mathbf{A}-\mathbf{C})$ were as described for Figure I.

Bjeldanes, 1987; Ge et al, 1999; Staub et al, 2002). Therefore, the in vitro effect of I3C may be partially attributed to its dimeric product, DIM. Hence, Chinni and Sarkar's (2002) study on Akt inactivation may support our findings regarding the apoptotic pathway of DIM in PC3 cell lines. Akt, a protein kinase, was shown to inhibit apoptosis and the processing of pro-caspases to their active forms, by delaying mitochondrial changes. Akt promotes cell survival by inhibiting the release of cytochrome $c$ from the mitochondria (Kennedy et al, 1999) and phosphorylating and inactivating caspase 9 (Cardone et al, 1998).

In conclusion, in this study we provide evidence that the indole derivative, DIM, induces apoptosis in human PC3 prostate cancer cells, through the mitochondrial pathway. Our results may contribute to a better understanding of the molecular mechanisms by which DIM exerts its effects in prostate cancer cells and tumours. These findings may lead to the development of new therapeutic strategies for the treatment of androgen-independent prostate malignancy, for which there is no effective life-prolonging therapy.

\section{REFERENCES}

Abate-Shen C, Shen MM (2000) Molecular genetics of prostate cancer. Genes Dev 14: 2410-2434

Bonnesen C, Eggleston IM, Hayes JD (2001) Dietary indoles and isothiocyanates that are generated from cruciferous vegetables can both stimulate apoptosis and confer protection against DNA damage in human colon cell lines. Cancer Res 61: 6120-6130

Bortner CD, Oldenburg NBE, Cidlowski JA (1995) The role of DNA fragmentation in apoptosis. Trends Cell Biol 5: 21-26

Bossy-Wetzel E, Newmeyer DD, Green DR (1998) Mitochondrial cytochrome $c$ release in apoptosis occurs upstream of DEVD-specific caspase activation and independently of mitochondrial transmembrane depolarization. EMBO J 17: $37-49$

Bradfield CA, Bjeldanes LF (1987) High-performance liquid chromatographic analysis of anticarcinogenic indoles in Brassica oleracea. J Agric Food Chem 35: 46-49

Bradford MM (1976) A rapid and sensitive method for the quantitation of microgram quantities of protein utilizing the principle of protein-dye binding. Anal Biochem 72: 248-254

Bruckheimer EM, Kyprianou N (2000) Apoptosis in prostate carcinogenesis. Cell Tissue Res 301: 153-162

Cardone MH, Roy N, Stennicke HR, Salvesen GS, Franke TF, Stanbridge E, Frisch S, Reed JC (1998) Regulation of cell death protease caspase-9 by phosphorylation. Science 282: $1318-1321$

Carter TH, Liu K, Ralph W, Chen D, Qi M, Fan S, Yuan F, Rosen EM, Auborn KJ (2002) Diindolylmethane alters gene expression in human keratinocytes in vitro. J Nutr 132: $3314-3324$

Chen DZ, Qi M, Auborn KJ, Carter TH (2001) Indole-3-carbinol and diindolylmethane induce apoptosis of human cervical cancer cells and in murine HPV16-transgenic preneoplastic cervical epithelium. J Nutr 131: 3294-3302 
Chinni SR, Li Y, Upadhyay S, Koppolu PK, Sarkar FH (2001) Indole-3carbinol (I3C) induced cell growth inhibition, G1 cell cycle arrest and apoptosis in prostate cancer cells. Oncogene 20: 2927-2936

Chinni SR, Sarkar FH (2002) Akt inactivation is a key event in indole3-carbinol-induced apoptosis in PC3 cells. Clin Cancer Res 8: $1228-1236$

Cohen JH, Kristal AR, Stanford JL (2000) Fruit and vegetable intakes and prostate cancer risk. J Natl Cancer Inst 92: 61-68

Cosulich SC, Savoy PJ, Clarke PR (1999) Bcl-2 regulates amplification of caspase activation by cytochrome $c$. Curr Biol 9: 147-150

Crawford ED (2003) Epidemiology of prostate cancer. Urology 62: 3-12

De Kruif CA, Marsman JW, Venekamp JC, Falke HE, Noordhoek J, Blaauboer BJ, Wortelboer HM (1991) Structure elucidation of acid reaction products of indole-3-carbinol: detection in vivo and enzyme induction in vitro. Chem Biol Interact 80: 303-315

Dragsted LO, Strube M, Larsen JC (1993) Cancer-protective factors in fruits and vegetables: biochemical and biological background. Pharmacol Toxicol 72(Suppl): $116-135$

Fares FA, Ge X, Yannai S, Rennert G (1998) Dietary indole derivatives induce apoptosis in human breast cancer cells. Adv Exp Med Biol 451: $153-157$

Ge X, Fares FA, Yannai S (1999) Induction of apoptosis in MCF-7 cells by indole-3-carbinol is independent of p53 and bax. Anticancer Res 19: $3199-3204$

Ge X, Yannai S, Rennert G, Gruener N, Fares FA (1996) 3,3'Diindolylmethane induces apoptosis in human cancer cells. Biochem Biophys Res Commun 228: 153-158

Grubb DR, Ly JD, Vaillant F, Johnson KL, Lawen A (2001) Mitochondrial cytochrome $c$ release is caspase-dependent and does not involve mitochondrial permeability transition in didemnin B-induced apoptosis. Oncogene 20: 4085-4094

Jain MG, Hislop GT, Howe GR, Ghadirian P (1999) Plant foods, antioxidants, and prostate cancer risk: findings from case-control studies in Canada. Nutr Cancer 34: 173-184

Kaufmann SH, Desnoyers S, Ottaviano Y, Davidson NE, Poirier GG (1993) Specific proteolytic cleavage of poly(ADP-ribose) polymerase: an early marker of chemotherapy-induced apoptosis. Cancer Res 53: $3976-3985$
Kedmi M, Yannai S, Haj A, Fares FA (2003) Indole-3-carbinol and 3,3'diindolylmethane induce apoptosis in human prostate cancer cells. Food Chem Toxicol 41: 745-752

Kennedy SG, Kandel ES, Cross TK, Hay N (1999) Akt/protein kinase B inhibits cell death by preventing the release of cytochrome $c$ from mitochondria. Mol Cell Biol 19: 5800-5810

Kolonel LN, Hankin JH, Whittemore AS, Wu AH, Gallagher RP, Wilkens LR, John EM, Howe GR, Dreon DM, West DW, Paffenbarger RS (2000) Vegetables, fruits, legumes and prostate cancer: a multiethnic casecontrol study. Cancer Epidemiol Biomarkers Prev 9: 795-804

Leong H, Firestone GL, Bjeldanes LF (2001) Cytostatic effects of 3,3'diindolylmethane in human endometrial cancer cells result from an estrogen receptor-mediated increase in transforming growth factor- $\alpha$ expression. Carcinogenesis 22: 1809-1817

Li Y, Li X, Sarkar FH (2003) Gene expression profiles of I3C- and DIMtreated PC3 human prostate cancer cells determined by cDNA microarray analysis. J Nutr 133: $1011-1019$

Lou X, Budihardjo I, Zou H, Slaughter C, Wang X (1998) Bid, a bcl-2 interacting protein, mediates cytochrome $c$ release from mitochondria in response to activation of cell surface death receptors. Cell 94: 481-490

Nunez G, Benedict MA, Hu Y, Inohara N (1998) Caspases: the proteases of the apoptotic pathway. Oncogene 17: 3237-3245

Saraste A, Pulkki K (2000) Morphologic and biochemical hallmarks of apoptosis. Cardiovasc Res 45: 528-537

Sheikh MS, Fornace AJ (2000) Role of p53 family members in apoptosis. I Cell Physiol 182: $171-181$

Staub RE, Feng C, Onisko B, Bailey GS, Firestone GL, Bjeldanes LF (2002) Fate of indole-3-carbinol in cultured human breast tumor cells. Chem Res Toxicol 15: $101-109$

Strasser A, O'Connor L, Dixit VM (2000) Apoptosis signaling. Annu Rev Biochem 69: $217-245$

Tang DG, Porter AT (1997) Target to apoptosis: a hopeful weapon for prostate cancer. Prostate 32: 284-293

Tavani A, La Vecchia C (1995) Fruit and vegetable consumption and cancer risk in a Mediterranean population. Am J Clin Nutr 61: 1374S-1377S

Verhoeven DTH, Verhagen H, Goldbohm RA, van den Brandt PA, van Poppel GA (1997) Review of mechanisms underlying anticarcinogenicity by Brassica vegetables. Chem Biol Interact 103: 79-129 